\title{
USO DE UM MAPA CONCEITUAL ADAPTADO \\ ENVOLVENDO ATIVIDADES LÚDICAS PARA O ENSINO DE QUÍMICA
}

\section{Use of an adapted conceptual map involving playful activities for chemical education}

\author{
Edemar Benedetti Filho (edemar@ufscar.br) \\ Universidade Federal de São Carlos, Departamento de Física, Química e Matemática \\ Alexandre Donizeti Martins Cavagis (cavagis@ufscar.br) \\ Universidade Federal de São Carlos, Departamento de Física, Química e Matemática \\ Luzia Pires dos Santos Benedetti (luziabenedetti@yahoo.com.br) \\ Universidade Federal de São Carlos, Departamento de Física, Química e Matemática \\ João Batista dos Santos Júnior (joaobats@ufscar.br) \\ Universidade Federal de São Carlos, Departamento de Física, Química e Matemática \\ Ana Paula Leal Jacob (anapaulalj_2@ @hotmail.com) \\ Universidade Federal de São Carlos, Departamento de Física, Química e Matemática
}

Resumo: O emprego de uma aprendizagem motivadora e significativa é foco de estudos de diversos pesquisadores na área de Ensino. Este trabalho teve como objetivo principal elaborar e avaliar a aplicação de uma atividade lúdica, que consistiu de um jogo de tabuleiro, adaptado a um mapa conceitual e aplicado na primeira série do Ensino Médio da rede pública, para revisão de assuntos de Química. Os resultados, obtidos por meio de análises de questionários e observações, registradas em diário de campo demonstraram a importância do jogo na aprendizagem significativa dos conceitos relacionados, bem como sua eficácia no processo de avaliação, na identificação de problemas e aprendizagem e na construção coletiva do conhecimento.

Palavras-chave: Mapas conceituais; Atividades lúdicas; Ensino de Química.

Abstract: The achievement of a motivating and meaningful learning is focus of studies by several researchers in the field of Education. The main objective of this work was to elaborate and evaluate the application of a playful activity, which consisted of a board game, adapted to a conceptual map and used in the first series of a public High School for the review of Chemistry subjects. The results, obtained by means of questionnaires analysis and observations, recorded in a field diary, demonstrated the importance of the game for the meaningful learning of related concepts, as well as its effectiveness in the evaluation process, for the identification of learning problems and for the collective construction of knowledge.

Keywords: Conceptual maps; Playful activities; Chemical Education.

\section{INTRODUÇÃO}


No Ensino de Ciências, uma das maiores dificuldades a ser superada é a inserção de novas metodologias de aprendizagem no sistema tradicional de ensino, uma vez que ele é o mais comumente utilizado pelos educadores em suas aulas. Tal modelo é unidirecional, em que o educador é o transmissor do conhecimento e o aluno um receptor, alguém que geralmente não pode expor livremente seu pensamento ou sua opinião sobre o assunto exposto. Dessa maneira, o estudante recebe e armazena as informações, mecanicamente, e as memoriza, podendo não ter condições de reproduzilas em outras situações, sendo que, em grande parte das vezes, o docente não é capaz de verificar deficiências de aprendizagem que seus alunos porventura possam apresentar.

Segundo Krasilchik (2004), citado em Castro e Costa (2011), a maneira unidirecional lecionada em aulas tradicionais gera desinteresse nos alunos e, como consequência, um baixo rendimento escolar, ocasionando ineficiência no processo de ensino e aprendizagem. $\mathrm{O}$ desinteresse da parte dos discentes é um dos maiores desafios do educador, que precisa despertar a vontade de aprender em seus alunos, sendo essa a força motriz para um processo de ensino e de aprendizagem mais eficaz. Dessa forma, um professor que inova em suas aulas poderá gerar situações que estimularão os estudantes a aprender e apreciar a Ciência.

Nessa perspectiva, as atividades lúdicas podem desempenhar um importante papel motivador ao ensino e aprendizagem de conceitos científicos, ajudando o estudante a desenvolver diferentes formas de pensamento, enriquecendo e ampliando sua formação, exercendo o educador um papel de orientador, estimulador e avaliador desse processo. Segundo Ferreira (2001, p. 430 e 439), a palavra jogo tem origem do latim "jocus", que significa brincadeira, divertimento, ou seja, todo movimento que vai ter como objetivo produzir prazer quando executado, contexto no qual estão inseridos os jogos didáticos. Portanto, o emprego de atividades lúdicas pode contribuir para despertar nos estudantes outras habilidades, tais como a melhora na cooperação com os colegas e interação com o professor, elaboração e apresentação de pontos de vista, aumento da desenvoltura, e situações que permitem lidar com possíveis derrotas. Segundo Pinto (2009, p. 16), o jogo permite uma maior socialização do grupo escolar, sendo dessa forma positivo para a aprendizagem.

De acordo com Costa et al. (2019), é importante que haja diversificação nos processos metodológicos utilizados em sala de aula: 
As dificuldades supracitadas podem estar associadas ao uso de aulas tradicionais, que não favorecem a assimilação dos assuntos. Por isso, a necessidade do uso de novas metodologias e novos recursos didáticos leva o educador a buscar estratégias que favoreçam a aprendizagem do aluno. (COSTA et al., 2019, p. 81).

Considerando o exposto, o presente trabalho tem como objetivo aplicar um mapa conceitual, adaptado à forma de atividade lúdica, com a finalidade de verificar a aprendizagem nas relações referentes à estrutura da matéria, por meio de um jogo didático de tabuleiro, intitulado "Formação Química", aplicado para alunos do $1^{\circ}$ ano do Ensino Médio, em duas Escolas Estaduais de uma cidade do interior do Estado de São Paulo.

\section{REFERENCIAL TEÓRICO}

Atualmente, as atividades lúdicas têm feito parte do ensino e aprendizagem de conceitos ao longo de todo o processo formativo, embora já fosse tema de discussão pelos grandes filósofos gregos. Platão (427-348 a.C.) defendia a importância de se "aprender brincando", enquanto Aristóteles sugeria que as crianças deveriam aprender com jogos de simulação dos adultos. Para eles, o jogo deveria ser um momento de descansar a mente, algo oposto ao trabalho. Percebe-se, aqui, que ambos defendiam a relevância dos jogos, tanto para instruir como para divertir.

Em Roma, naquela mesma época, utilizavam-se os jogos físicos para formar soldados aptos para as batalhas. Também se fazia uso de atividades lúdicas no processo de alfabetização, quando doceiras preparavam guloseimas, em formato de letras, para que fossem utilizadas no ensino de leitura e escrita às crianças (KISHIMOTO, 1996).

Segundo Cunha (2012), o uso de atividades lúdicas voltadas à aprendizagem das Ciências se deu no século XVIII, apenas pela realeza e aristocracia. Rapidamente, porém, essas atividades foram se tornando populares e, com o término da Revolução Francesa, surgiram mais inovações pedagógicas no processo de ensino, tendo as atividades lúdicas uma contribuição muito interessante ao meio educacional. Por exemplo, no ensino de Matemática e Física, utilizavam-se figuras geométricas em formatos de cubos e esferas, estabelecendo-se relações entre conceitos físicos e matemáticos. Atualmente, as atividades lúdicas têm se consolidado como metodologias de ensino cada vez mais importantes. 
Para que uma atividade lúdica seja caracterizada como educacional, os aspectos lúdico e educativo devem estar em equilíbrio. A função lúdica relaciona-se à diversão e ao prazer proporcionados durante a atividade, enquanto a função educativa refere-se à apreensão de conhecimentos, habilidades e saberes, ao longo do processo de aprendizagem. Para conseguir uma boa relação entre as funções lúdica e educativa, as atividades devem ser planejadas e controladas pelo educador, a fim de que sua introdução em sala de aula alcance o objetivo esperado.

Segundo Freitas e Salvi (2008), o jogo lúdico tem a propriedade de ser educativo e se diferenciar dos outros jogos, devido à possibilidade de autoconhecimento do aprendiz, respeito pelo próximo, por si mesmo, integração entre alunos e professores, servindo de estímulo ao aprender, associando-o com prazer e alegria (CASTRO; COSTA, 2011).

As atividades lúdicas têm estado bastante presentes no Ensino de Ciências, fato que se comprova pela diversa quantidade de trabalhos publicados envolvendo tal metodologia de ensino (OLIVEIRA et al., 2015; SILVA et al., 2015; SOUZA et al., 2018; SOUZA; SILVA, 2018; SILVA; GUERRA, 2018; COSTA et al., 2019, SILVA et $a l$., 2019, entre inúmeras outras). Assim, buscou-se, por meio deste trabalho, uma adaptação para uma aprendizagem lúdica envolvendo a utilização de mapas conceituais.

Moreira e Masini (2006) explicam que mapas conceituais constituem-se como uma ferramenta desenvolvida por Novak e Gowin e, de uma maneira simplificada, assemelham-se a diagramas hierárquicos que procuram refletir, em duas dimensões, a estrutura ou organização conceitual de uma disciplina ou parte dela. Essa ferramenta é fundamentada na teoria da aprendizagem significativa de Ausubel.

Moreira (1999) aponta que aprender significativamente implica atribuir significados, enquanto que, na aprendizagem mecânica, a atribuição dos significados não implica relação com o conhecimento pré-existente do sujeito, ou seja, o novo conhecimento é armazenado de forma arbitrária e literal na mente do indivíduo, não criando vínculos com a estrutura cognitiva do aprendiz. Já na aprendizagem significativa, conceitos anteriores interagem com os novos conhecimentos e servem de base para a atribuição de novos significados, que vão também se modificando em função dessa interação. 
Os mapas conceituais foram estruturados para instrumentalizar a teoria da aprendizagem significativa, constituindo uma importante ferramenta para apoiar o processo de ensino e aprendizagem. Quando se elaboram mapas conceituais, há uma representação na forma de estrutura gráfica para os conteúdos que se relacionam com as estruturas cognitivas, interligando os conceitos ordenados e, quando o executam em um segundo momento, há colocações de novas informações que são acrescentadas, o que torna possível verificar os mecanismos da cognição humana (AUSUBEL et al., 1978).

A idealização para um mapa conceitual pode se proceder de diversas maneiras, de acordo com a disposição dos conceitos principais e subjacentes. Geralmente, ocorre uma relação hierárquica, seguindo um caminho de pensamento, podendo ser linear ou radial, de cima para baixo ou vice-versa, porém, sempre estabelecendo um padrão definido. Os elementos organizadores, que são observados, apresentam uma importância na teoria da aprendizagem significativa, baseando-se em diversos princípios lógicos, tais como, as ideias relevantes ou apropriadas, os identificadores para um conteúdo relevante que já existia no sistema cognitivo.

O estabelecimento de relações entre ideias, proposições e conceitos fornecem outro processo da aprendizagem significativa. Os elementos já existentes dentro da estrutura cognitiva do indivíduo, apresentando um determinado grau de clareza, de estabilidade e de diferenciação, passam a formar novos significados e levam a aprendizagem a uma nova reorganização da estrutura cognitiva. Por exemplo, caso o aluno já tenha conceitos anteriores e fundamentados sobre a teoria e estáveis na estrutura cognitiva, há a possibilidade de vê-los como manifestações de um conceito mais abrangente. A reconciliação integrativa é a recombinação desses elementos de aprendizagem, proporcionada pela reorganização cognitiva do conhecimento, estabelecendo, assim, um tipo de relação significativa.

A simbiose entre o emprego de mapa conceitual e atividades lúdicas reforça a importância que a estrutura na construção do pensamento tem para a aprendizagem dos alunos. Segundo Tavares et al. (2018), é essencial para a elaboração dos mapas:

[...] um esforço cognitivo para identificar os conceitos considerados mais importantes e para criação de proposições, além das reflexões e modificações que os discentes faziam cada vez que um novo conhecimento era incorporado a sua estrutura cognitiva. Foi notória a pré-disposição dos discentes em apropriar-se de mais informações e de encadear novos conceitos em seus mapas, o que representa um fator favorável ao processo de ensino e 
aprendizagem, como descreve a teoria de Ausubel. (TAVARES et al., 2018, p. 76).

\section{PROCEDIMENTOS METODOLÓGICOS}

Este trabalho foi planejado com base nas seguintes etapas: pesquisa, escolha do conteúdo, desenvolvimento do mapa conceitual (tabuleiro, cartas e regras) e elaboração de um questionário avaliativo para a proposta pedagógica.

O material lúdico foi montado e elaborado a partir de uma adaptação para um mapa conceitual sobre estrutura da matéria (do que é constituída, tipos de materiais, como se arranjam, como se caracterizam etc.), empregando o software Adobe Illustrator ${ }^{\mathrm{TM}}$ para confecção do tabuleiro e das cartas.

A Figura 1 ilustra o tabuleiro montado e as cartas distribuídas na atividade. O tabuleiro é constituído de vinte e duas casas para preencher com as cartas e dez casas já preenchidas, as quais são necessárias para direcionar a formação do mapa conceitual adaptado ao tabuleiro. Foram elaboradas quarenta cartas para o jogo, sendo que dezoito cartas não fazem parte da constituição deste mapa conceitual. 


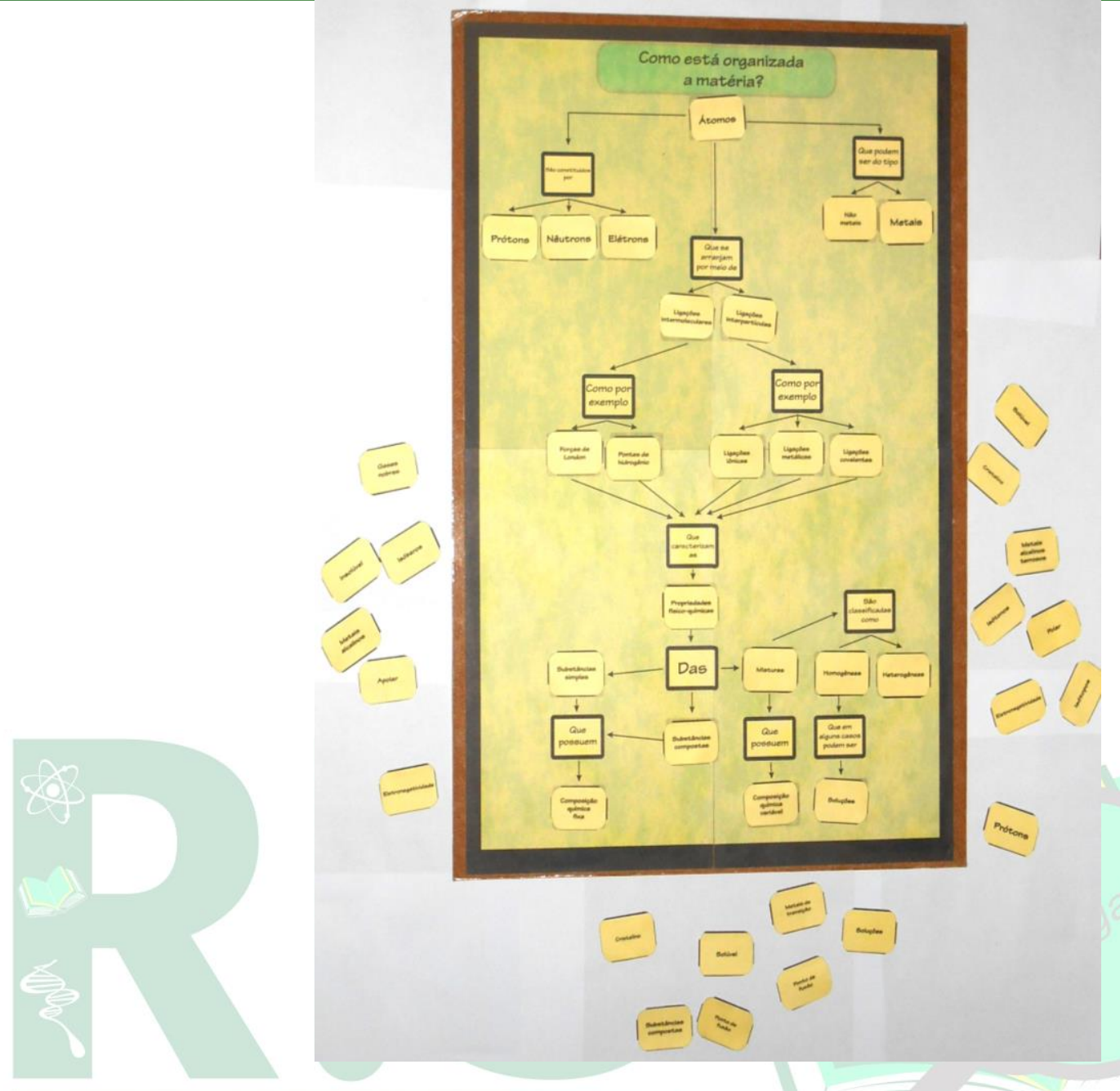

Figura 1: Tabuleiro impresso em cores sobre um papel branco, de espessura $180 \mathrm{~g} / \mathrm{cm}^{2} \mathrm{e}$ recortado, colado sobre papelão, bem como as cartas utilizadas.

Fonte: Os autores.

O trabalho foi aplicado em salas do $1^{\circ}$ ano do Ensino Médio de duas escolas públicas estaduais de uma cidade do interior do Estado de São Paulo, para um total de 98 alunos no início do segundo semestre. Para coletar os dados da pesquisa, foram utilizadas gravações de áudio, questionário, e as anotações em diário de campo. As gravações em áudio foram transcritas para melhor análise dos diálogos ocorridos durante a aplicação do jogo. O gravador foi posicionado no centro da sala, em um canto superior, para captar bem toda a movimentação. O diário de campo foi empregado para anotar intervenções que ocorriam durante a aplicação do jogo e as observações comportamentais dos alunos. A análise dos dados foi pautada em uma abordagem qualitativa, fundamentando-se nas observações encontradas durante a pesquisa (BOGDAN; BIKLEN, 2000), e o questionário representou uma amostragem quantitativa das observações descritas. Segundo Gil (1999, p.128), o uso do 
questionário é caracterizado: como a técnica de investigação composta por um número até mesmo elevado de questões, apresentadas por escrito às pessoas, tendo por objetivo o conhecimento de opiniões, crenças, sentimentos, interesses, expectativas, situações vivenciadas etc. Assim, aplicou-se o questionário para observar ideias e conceitos prévios dos alunos sobre composição da matéria.

Após a aplicação da atividade, realizou-se um debate com os alunos, mediado pelo docente da disciplina, sobre o tema desenvolvido, a fim de reforçar a interação entre os estudantes e os conhecimentos abordados.

\section{RESULTADOS E DISCUSSÃO}

Optou-se pela aplicação de uma atividade lúdica nas semanas letivas iniciais, na disciplina de Química, a fim de ajudar na quebra do paradigma de que a Ciência é chata e apenas decorativa. A proposta foi trazer o diálogo para a sala de aula e melhorar a relação aluno-professor, uma vez que o docente pode avaliar mais profundamente quais os problemas interpretativos que seus alunos possuíam em sua formação advinda do Ensino Fundamental. Segundo Driver et al. (1999), a aprendizagem ocorre mais significativamente em um ambiente coletivo, onde há troca de informações:

Conferir significado é, portanto, um processo dialógico que envolve pessoas em conversação e a aprendizagem é vista como o processo pelo qual os indivíduos são introduzidos em uma cultura por seus membros mais experientes. (DRIVER et al., 1999).

Esta estratégia de ensino propiciou um processo de avaliação da aprendizagem por meio do diálogo e aprimoramento de outras competências dos alunos, tais como a argumentação e a reflexão sobre os conteúdos abordados. Tais habilidades podem ser mais facilmente desenvolvidas em uma proposta de ensino construtivista, em vez da transmissão unilateral de conteúdos e a sua memorização. A presente pesquisa demonstrou que o diálogo entre os alunos foi essencial para a consolidação e verificação da aprendizagem, assim como para nortear os limites de conhecimento que o docente poderá abordar em aulas futuras.

Durante a aplicação da atividade, observaram-se participações espontâneas dos estudantes. A facilidade da metodologia lúdica incentiva o diálogo entre os alunos, favorecendo ao professor realizar uma melhor avaliação do conteúdo abordado. As frases a seguir ilustram a interação entre o conteúdo e a metodologia. 
“Eu sei isso, mas não lembro!”. Aluno MMB

“Como tava no caderno!”. Aluna RHJS

Observa-se que o diálogo é importante para o professor verificar se houve entendimento do conteúdo e qual a profundidade do conhecimento alcançado pelos alunos, trazendo ideias para futuras intervenções em sala de aula com propostas pedagógicas que possam melhorar a construção do conhecimento pelos alunos.

Visando a avaliar a contribuição do jogo na aprendizagem de conceitos de Química, foi aplicado um questionário para verificar se a atividade lúdica teria influenciado, diretamente, no aprimoramento da capacidade de correlação conceitual dos estudantes. Nesse questionário, havia questões sobre assuntos envolvidos no jogo (Matéria e teoria atômica) e questões sobre propriedades físicas, um assunto não abordado no jogo, mas que, assim como os anteriormente citados, já havia sido ministrado em aulas tradicionais. A Figura 2 mostra o desempenho comparativo dos estudantes, apresentando os percentuais de acertos e erros em questões conceitualmente correlacionadas aos temas "Matéria" e "Teoria atômica", que foram revistos no jogo e, comparativamente, os acertos e erros em questões relacionadas ao tema "Propriedades físicas", não trabalhado no jogo.

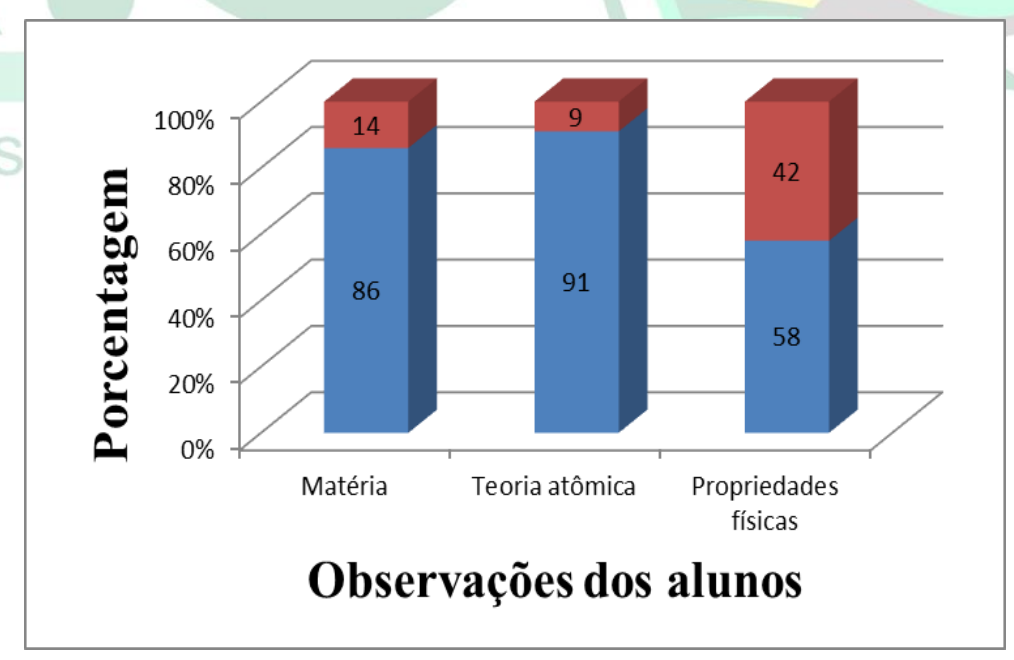

Figura 2: Percentuais de acertos (azul) e erros (vermelho) em questões interpretativas relacionadas a assuntos abordados no jogo (Matéria e Teoria atômica) e não abordado no jogo (Propriedades físicas).

Fonte: Os autores.

As respostas obtidas reforçaram a revisão do conteúdo que a atividade lúdica proporcionou e algumas colocações dos estudantes confirmam tal constatação, 
relacionando os momentos de reflexões deles próprios sobre os conteúdos pedagógicos trabalhados. O jogo permitiu verificar ainda que o tema "Propriedades físicas" deve ser mais bem explorado pelo professor. A concepção dos alunos em relação a este tema não é clara, revelando dificuldades de aprendizagem que o jogo ajudou a detectar. Os relatos a seguir ilustram momentos de revisão do conteúdo e discussões que os alunos realizaram no decorrer da atividade:

\title{
"Sim, e de uma forma inteligente". Aluno CV
}

“Contemplou sim, o conteúdo do jogo foi passado durante as aulas". Aluna AMQ

Outro ponto abordado relacionou-se à opinião dos estudantes sobre como os jogos didáticos podem contribuir na aprendizagem para expandir seus próprios conhecimentos. Nesse caso, ficou claro o entusiasmo com essa novidade desenvolvida na sala de aula, e com o prazer que tal método de aprendizagem proporcionou.

\section{"Uma maneira divertida e diferente". Aluna AMJ}

"É um modo de aprendizado diferente e interessante". Aluna TRAP

“Acho que seria incrível se todas as aulas pudessem ser assim”. Aluno AAM

Tal observação também é corroborada no trabalho de Moyles (2002):

\begin{abstract}
Os jogos educativos promovem situações de ensino-aprendizagem e aumentam a construção do conhecimento, introduzindo atividades lúdicas e prazerosas, desenvolvendo a capacidade de iniciação e ação ativa e motivadora. A estimulação, a variedade, o interesse, a concentração e a motivação são igualmente proporcionados pela situação lúdica. (MOYLES, 2002, p. 21).
\end{abstract}

As respostas citadas evidenciam que os alunos se divertiram durante a atividade, sentiram-se entusiasmados e acharam que o jogo foi um modo diferente e divertido de rever e discutir assuntos relacionados à constituição da matéria. As análises observadas revelaram que o jogo também pode ser uma boa ferramenta para avaliação da aprendizagem, pois a interação e o diálogo com o professor foram importantes no sentido de verificar deficiências de aprendizagem, quebrando possíveis barreiras entre o aluno e o professor, deixando os estudantes mais descontraídos para exporem suas lacunas formacionais.

“Ajuda a estimular a aprendizagem, porque aprendemos jogando, mas ao mesmo tempo, estudando. Estudando de uma forma divertida". Aluna AMQ 


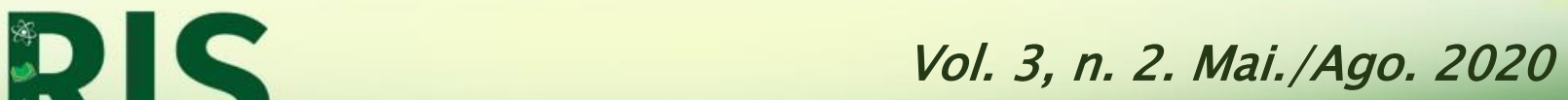

ISSN: 2595- 4520

Observou-se, também, que $77 \%$ dos alunos participantes acharam que o jogo abordou muito bem os conteúdos trabalhados durante as aulas de Química (apresentadas previamente pelo professor). As argumentações seguintes ilustram tal situação:

"Fiquei surpresa. Não tinha feito ainda nada parecido". Aluno FGJ

“A abordagem é muito boa, por questão do modo de ensinar. Quando o professor tem uma dinâmica para ensinar o aluno, isso torna a aula melhor". Aluna PKL

"Que foi uma maneira muito boa de aprender Química". Aluna YMN

O modo de abordar conteúdos já trabalhados na forma de jogo agradou os alunos, principalmente por ser uma nova forma de demonstrar o que se sabe sobre os conteúdos, de uma maneira diferente da convencional, por meio de uma avaliação escrita.

Observou-se, a partir da análise do questionário, que a visão dos estudantes em relação à troca de conhecimentos com o seu grupo foi totalmente positiva, fato que se evidencia nas seguintes afirmações:

"Sim, porque todos demonstraram sua opinião e seu conhecimento sobre a matéria". Aluno RRA

"Sim, porque cada um falou o que sabia deixando o jogo mais fácil". Aluna CBB

A maioria dos alunos (96\%) respondeu no questionário que o jogo apresentou uma boa dinâmica, e isso mostra que o uso de jogos para verificação da aprendizagem pode ser uma estratégia dinâmica e atrativa. Um comentário ilustra bem tal observação:

"Foi ótimo, porque todos os integrantes do grupo ajudaram na montagem do diagrama". Aluna PKL

A realidade atual vivenciada pelos adolescentes, de conexão digital praticamente o tempo todo, identificando-os com o jogo enquanto ferramenta dinâmica e altamente interativa de ensino e aprendizagem, assim como a interação entre alunos e professor, proporcionada pela atividade, foram essenciais para viabilizar uma situação de aprendizagem na qual o processo cognitivo se tornou mais significativo para todos os participantes.

Verificou-se que o jogo foi uma alternativa para os estudantes organizarem e avaliarem seu próprio conhecimento na disciplina de Química. Foi praticamente unânime entre eles que uma atividade lúdica seria uma ótima ferramenta a ser utilizada 
na verificação da aprendizagem, quando se refere à organização lógica do conhecimento individual. Dessa forma, o emprego de um mapa conceitual foi um caminho eficaz, reforçando a importância do diálogo e da troca de informações na construção do conhecimento. Tal verificação é corroborada por Tavares et al. (2018, p. 67): O uso de mapas conceituais como ferramenta pedagógica está ligado ao fato de sua elaboração possibilitar uma forma diferenciada de relacionar os conceitos, exigindo dos estudantes um pensamento integrado.

O diálogo que a atividade lúdica proporcionou na discussão dos conteúdos envolvidos, em contrapartida à aula tradicional, em que os alunos geralmente não dialogam sobre conteúdos didáticos (informação descrita pelo docente), demonstrou como os alunos desenvolveram a lógica em relação aos tópicos envolvidos. Isso auxiliou na verificação de quais problemas necessitavam ser revistos nas abordagens e estratégias de ensino em aulas futuras.

Os participantes acharam que o jogo foi uma maneira de organizar e avaliar seu próprio conhecimento, mesmo aqueles que pouco dialogavam com os colegas. Neste caso, a atividade proposta não foi exclusivamente um método de revisão, mas sim, uma ferramenta para induzir o aluno a pensar, a raciocinar e a refletir sobre o que foi ensinado pelo professor, expondo seus argumentos para os colegas e construindo diálogos discursivos envoltos por conclusões científicas, o que contribuiu para o desenvolvimento de habilidades e competências individuais e coletivas.

Leão et al. (2018) discorrem sobre a importância da verificação da aprendizagem significativa pelo docente, em consonância com a atividade lúdica empregada, reforçando a importância do mapa conceitual nesse contexto:

\begin{abstract}
A percepção e a compreensão das características que definem um conceito são essenciais para a elaboração de um mapa conceitual. E é justamente essa rede de conceitos que vai sendo formada na mente dos estudantes ao longo do processo de ensino e aprendizagem. Além da nota obtida através dos critérios preestabelecidos, o estudante torna explícitos os conceitos e proposições aprendidas, e o professor pode determinar as etapas para a organização de significados e identificar os conceitos mais relevantes ou os que ainda precisam ser mais desenvolvidos. (LEÃO et al., 2018, p. 415).
\end{abstract}

Durante a aplicação do jogo, os alunos demonstraram várias reações, como entusiasmo, interesse, nervosismo, ansiedade, impaciência e dedicação. Notou-se que a realização desse tipo de atividade lúdica em sala de aula serviu como estímulo ao interesse em saber mais sobre a disciplina. Ao término da atividade eram visíveis a 
empolgação, curiosidade e o desejo de realizar outras atividades como essa em aulas futuras. O professor da disciplina descreveu, em entrevista posterior, ter havido uma maior participação dos seus alunos durante a aula e em discussões de outros conteúdos.

Segundo relato do professor ministrante da disciplina no Ensino Médio, após a aplicação do jogo, os alunos apresentaram uma nítida mudança comportamental, observando-se maior interação entre eles, considerando que essa sala sempre foi dividida em grupos que não interagiam. $\mathrm{O}$ jogo foi muito importante nesse contexto social pois, além do objetivo didático principal, aproximou e promoveu diálogos entre alunos que anteriormente não se conversavam. Isso é importante para uma boa gestão em sala de aula, permitindo ao docente conduzir mais facilmente e de maneira mais eficaz seus conteúdos pedagógicos.

Segundo Felício e Soares (2018), com relação ao interesse dos alunos na atual conjuntura tecnológica:

Defendemos que a sala de aula deve ser modificada no sentido de despertar o interesse dos alunos para o conhecimento e não somente para a informação. Notamos que os alunos estão inseridos em uma cultura que perpassa as redes sociais e caminha até uma infinidade de jogos. Para eles, essa cultura é muito mais interessante do que os conhecimentos químicos em sala de aula. Se não nos atentarmos a tal aspecto, perderemos terreno para essa "concorrência". Nós, professores, sabemos da importância da química, tanto em nível pessoal, quanto em relação às suas aplicações na sociedade. Mas não estamos conseguindo fazer com que os alunos também entendam da mesma forma, imersos que estão em outras plataformas. $\mathrm{O}$ que buscamos são mecanismos diversos para que esse entendimento possa se tornar realidade. Pensamos e defendemos o uso do lúdico como uma dessas alternativas. (FELÍCIO; SOARES, 2018, p. 163).

Assim, é importante que os docentes se atentem ao interesse de seus alunos e que possam promover atividades mais dinâmicas que aquelas apresentadas no ensino tradicional. Nessa perspectiva, o emprego de atividades lúdicas pode contribuir para que os alunos tenham maior participação em sala de aula e como resultado, ocorra uma melhora significativa no processo de ensino e aprendizagem, ajudando assim o docente a conhecer e relacionar-se de uma maneira mais eficiente em sala de aula. Segundo Benedetti-filho et al. (2020), estas correlações são importantes para a formação dos alunos:

A importância da inserção de atividades lúdicas para revisão e consolidação de conceitos relacionados ao Ensino de Química e também para o melhoramento nas relações interpessoais em sala de aula. A atividade empregada permitiu retirar os alunos da situação passiva, imposta pela metodologia tradicional de ensino, propiciando uma aprendizagem mais 
prazerosa e significativa dos conceitos químicos, construída por meio de discussões em grupo conduzidas pelo professor de Química, que assumiu o papel de mediador e orientador na construção coletiva do conhecimento. (BENEDETTI-FILHO et al., 2020, p. 43).

\section{CONCLUSÃO}

Com base nos resultados obtidos neste trabalho, a utilização de um jogo de tabuleiro envolvendo uma adaptação de mapa conceitual mostrou-se uma ferramenta complementar promissora no processo de ensino e aprendizagem. A atividade lúdica contribuiu para que alunos do Ensino Médio pudessem, além de aprimorar sua aprendizagem, aperfeiçoar outras habilidades, tais como a melhora na desenvoltura para exposição de ideias em grupo.

O jogo foi desenvolvido para avaliar a aprendizagem significativa dos alunos, fundindo atividades lúdicas e adaptações de mapas conceituais e permitindo que os educandos vivenciassem uma visão mais ampla e prazerosa dos conteúdos abordados em sala de aula. Outra questão importante verificada foi a correlação entre conceitos vistos previamente e sua interpretação contextual com os demais participantes da atividade.

Proposto em formato de mapa conceitual, o jogo mostrou-se uma ferramenta para avaliação da aprendizagem, o que se constatou por meio das reações e expressões demonstradas pelos participantes. A atividade também foi válida para identificar problemas de aprendizagem, permitindo ao docente planejar revisões e aprofundamentos em conteúdos sobre os quais ficaram lacunas, além de analisar a organização conceitual e o nível de aprofundamento que os alunos já possuíam, por meio das jogadas realizadas.

No contexto da presente pesquisa, o lúdico foi fundamental, uma vez que favoreceu o desenvolvimento de atitudes e competências que, tradicionalmente, não são trabalhadas em sala de aula, como sociabilidade, espontaneidade, cooperatividade e criatividade. Os alunos puderam aprimorar relações cognitivas, afetivas e sociais, participando de uma aprendizagem significativa, por meio da construção coletiva do conhecimento.

Com a atividade lúdica, estabeleceu-se um ambiente descontraído, motivacional e prazeroso em sala de aula. Ficou evidente que esse tipo de atividade estimula o interesse dos estudantes pela disciplina de Química, geralmente muito baixo no sistema tradicional e unidirecional de ensino. 


\section{REFERÊNCIAS}

ANTUNES, J.; QUEIROZ, Z. F.; SANTOS, I. B. R.; LIMA, J. N. Ciclo criativo de jogos colaborativos: um método para criação de jogos educativos. Holos, v. 34, n. 2, p. 424-437, 2018.

AUSUBEL, D. P.; NOVAK, J. D.; HANESIAN, H. Educational psychology: a cognitive view. $2^{\mathrm{a}}$ ed. New York: Holt Rinehart and Winston, 1978.

BENEDETTI-FILHO. E; CAVAGIS, A. D. M.; BENEDETTI, L. P. S. Um jogo didático para revisão de conceitos químicos e normas de segurança em laboratórios de química. Química Nova na Escola, v. 42, n. 1, p. 37-44, 2020.

BOGDAN, R.; BIKLEN, S. Investigação qualitativa em educação. Porto: Porto Editora, 2000.

CASTRO, B. J.; COSTA, P. C. F. Contribuições de um jogo didático para o processo de ensino e aprendizagem de Química no ensino fundamental segundo o contexto da aprendizagem significativa. Revista Electrónica de Investigación en Ciencias, v. 6, n. 2, p. 25-37, 2011.

COSTA, E. A.; DUARTE, R. A. F.; GAMA, J. A. S. A gamificação da botânica: uma estratégia para a cura da "guerra botânica". Revista Insignare Scientia, v. 2, n. 4, p. 79 99, 2019.

CUNHA, M. B. Jogos no ensino de química: considerações teóricas para sua utilização em sala de aula. Química Nova na Escola, v. 34, n. 2, p. 92-98, 2012.

DRIVER, R.; ASOKO, H.; LEACH, J.; MORTIMER, E.; SCOTT, F. Construindo conhecimento científico na sala de aula. Química Nova na Escola, v. 9, n. 1, p. 31-40, 1999.

FELÍCIO, C. M.; SOARES, M. H. F. B. Da intencionalidade à responsabilidade lúdica: novos termos para uma reflexão sobre o uso de jogos no ensino de química. Química Nova na Escola, v. 40, n. 3, p. 160-168, 2018.

FERREIRA, A. B. H. Aurélio século XXI: o minidicionário da língua portuguesa. $5^{\mathrm{a}}$ ed. Rio de Janeiro: Nova Fronteira, 2001.

FREITAS, E. S.; SALVI, R. F. A Ludicidade no ensino de geografia: perspectiva para uma aprendizagem significativa. Anais do II Encontro Nacional de Aprendizagem Significativa. Canela, Brasil, 2008.

GIL, A. C. Métodos e técnicas de pesquisa social. 5. ed. São Paulo, Atlas, 1999. 
KISHIMOTO, T. M. Jogo, brinquedo, brincadeira e educação. São Paulo, Cortez, 1996

KRASILCHIK, M. Prática de ensino de biologia. São Paulo, EDUSP, 2004.

LEÃO, M. F.; DUTRA, M. M.; ALVES, A. C. T. Estratégicas didáticas voltadas para o ensino de ciências: experiências pedagógicas na formação inicial de professores. Uberlândia, Edibrás, 2018.

MOREIRA, M. A. Teorias de aprendizagem. São Paulo, EPU, 1999

MOREIRA, M. A.; MASINI, E. F. S. Aprendizagem significativa: a teoria de aprendizagem de David Ausubel. São Paulo, Centauro Editora, 2006.

MOYLES, J. R. Só brincar? O papel do brincar na educação infantil. Tradução: Maria Adriana Veronese. Porto Alegre, Artmed, 2002.

OLIVEIRA, J. S.; SOARES, M. H. F. B.; VAZ, W. F. Banco químico: um jogo de tabuleiro, cartas, dados, compras e vendas para o ensino do conceito de soluções.

Química Nova na Escola, v. 37, n. 4, p. 285-293, 2015.

PINTO, L. T. O Uso dos Jogos didáticos no Ensino de Ciências no Primeiro Segmento do Ensino Fundamental da rede Municipal Pública de Duque de Caxias. Dissertação de Mestrado - Instituto Federal de Educação, ciências e Tecnologia. Neópolis - RJ, 2009.

SILVA, B.; CORDEIRO, M. R.; KILL, C. K. B. Jogo didático investigativo: uma ferramenta para o ensino de química inorgânica. Química Nova na Escola, v. 37, n. 1, p. $37-34,2015$

SILVA, C. M. A.; GUERRA, A. C. O. pHQuim: uma abordagem lúdica do tema pH. Revista de Educação, Ciências e Matemática, v. 8, n. 3, p. 201-213, 2018.

SILVA, I. V.; FONSECA, L. M.; TAVARES, C. S.; CARMO, A. M.; SANTANA, A. C. Desenvolvimento de jogos didáticos auxiliares em práticas transdisciplinares e de alfabetização científica no ensino das ciências da natureza. Revista Insignare Scientia, v. 2, n. 4, p. 349-363, 2019.

SOUZA, L. C. M.; LOJA, L. F. B.; PIRES, D. A. T. Bingo periódico: atividade lúdica no ensino de tabela periódica. Revista Thema, v. 15, n. 4, p. 1277-1293, 2018.

SOUZA, T. P.; SILVA, P. F. K. O ensino de química e atividades lúdicas: o que pensam os estudantes? Revista Latino-Americana de Estudos em Cultura e Sociedade, v. 4, n. 1, p. 1-11, 2018. 
TAVARES, L. C.; MÜllER, R. C. S.; FERNANDES, A. C. O uso de mapas conceituais como ferramenta metacognitiva no ensino de química. Amazônia - Revista de Educação em Ciências e Matemáticas, v. 14, n. 29, p. 63-78, 2018.

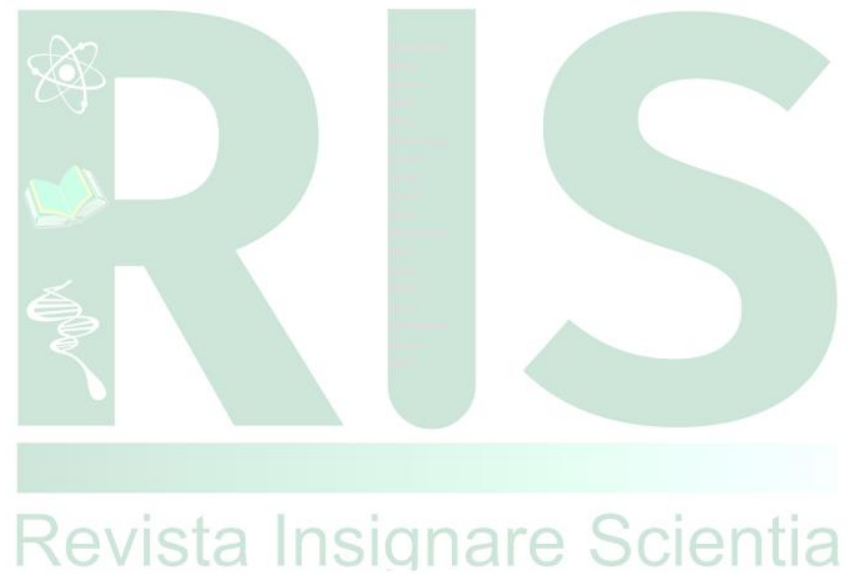

